\title{
Surges of Development and Techno-Economic Paradigms. A Review Essay of the Festschrift for Carlota Perez.
}

\author{
Walter Scherrer \\ University of Salzburg \\ walter.scherrer@sbg.ac.at
}

REVIEW OF

Techno-Economic Paradigms. Essays in Honour of Carlota Perez, edited by Wolfgang Drechsler, Rainer Kattel and Erik S. Reinert. London and New York 2009, Anthem Press, ISBN-13: 9781843317852.

\section{Introduction}

Although it might be difficult to agree on a precise definition of what mainstream economics is, it is perhaps easier to agree that mainstream economics did not succeed in explaining ex ante the financial meltdown in 2008 and the subsequent disturbances in the global economy. Yet outside this mainstream, there have been writers - not many, but Carlota Perez among them - who envisaged clearly why, how, and under what circumstances economic tensions would unfold into a fundamental break in economic history. In her major work Technological Revolutions and Financial Capital - The Dynamics of Bubbles and Golden Ages (Perez, 2002), Perez developed a model founded on elements from Kondratiefftype cycle theories and neo-Schumpeterian or evolutionary research on innovation and technological trajectories. At the core of her model is the concept of great surges of socio-economic development, which reflect different techno-economic paradigms (TEP). To mark the $70^{\text {th }}$ birthday of Carlota Perez, three of her colleagues from Tallinn University of Technology - a stronghold of the TEP model - edited Festschrift TechnoEconomic Paradigms, bringing together important writers and fellow contributors, mostly to the areas of Neo-Schumpeterian evolutionary 
economics and cycle theory, to acknowledge her outstanding contribution to these fields.

The next section of the paper will give a brief overview of Perez's model of TEP and surges of development. Selected topics that are dealt with in the Festschrift will then be discussed, in particular the role of financial markets within the dynamics of development surges, and the roles of government and public administration in coping with a change of TEP. The paper concludes with an overview of possible future development surges and of how to prepare for associated TEPs, with a section highlighting the significance of the Perez model for a distinct development strategy for Latin America.

\section{Carlota Perez's model of development surges in a nutshell}

The emergence of new combinations of new technologies, new modes of organisation of economic relations, and new infrastructure provides huge incentives for entrepreneurs; such technological revolutions have occurred every 40 to 60 years and have generated surges of development. Five such technological revolutions and interrelated surges have taken place since the coming of the industrial society in the late $18^{\text {th }}$ century, and each of these revolutions has been "accompanied by a set of 'best practice' principles, in the form of a techno-economic paradigm, which breaks the existing organisational habits in technology, the economy, management and social institutions" (Perez, 2002, p. 7). In one of his last original contributions, "Schumpeter's Business Cycles and Techno-Economic Paradigms", the late Christopher Freeman emphasises this feature of Perez's model showing that the concept of a TEP is much wider than clusters of innovations or even technology systems. The TEP concept refers to "a combination of interrelated product and process, technical, organisational and managerial innovations, opening up an unusually wide range of new investment and profit opportunities" (Freeman in Festschrift for Carlota Perez [FCP], p. 136). The key factors or key inputs of each TEP are characterised by clearly perceived and rapidly falling relative cost, an almost unlimited availability of supply over long periods, and a clear potential for use or incorporation of new key factors in many products and processes throughout the economic system.

At the beginning of the installation phase of each TEP (see Figure 1) is a technological "big bang", such as Henry Ford's Model T in 1908, as the start of mass production, or Intel's first microprocessor in 1971 as the 
start of modern information technology. In the installation phase's first part ("irruption"), the new sets of technologies start from a small industrial base, but soon spread far beyond the confines of the industries where they originally emerged and provide a set of interrelated technologies and organisational principles that allow a step change in potential productivity in practically all economic activities (Perez, 2002, p. 8). In the frenzy phase, both the wealth-creating potential of the new paradigm and the exhaustion of the prevailing old paradigm become apparent. Financial capital now takes over and the impact of the great surge of development becomes more and more visible. This is the time of exuberance when entrepreneurs and investors try to find the best opportunities created by the new technology - this process of modernisation of the economy is based on Schumpeterian creative destruction. The enormous financial success of some key actors - Henry Ford or Bill Gates - attracts more and more capital to ventures based on the new TEP. Stock markets boom, and even people with modest salaries turn into »hopeful 'investors'" (Perez, 2002 , p. 3), before the emergent bubble is finally set to burst.

In the deployment phase of a TEP, its potential has already become apparent and it can become fully realised. Infrastructure has already been established, and large parts of the population have the physical equipment, knowledge and skills required to utilise the new technologies. In the synergy phase, which is the first part of deployment of the now dominant TEP, all conditions are favourable to production and to the full flourishing of the new paradigm (Perez, 2002, p. 47). With the quick money already having been made (and some of it lost) during the frenzy period, investors now turn to the real economy, rendering a "golden age" for a technology which impacts on all parts of society. Although many signs of success and prosperity are still around, every TEP finally reaches a maturity phase in which its potential to further increase productivity is exhausted and its attractiveness dwindles for at least parts of the population. While those who have reaped the full benefit of the "golden age" still praise its virtues, those whose belief in the paradigm's promises has been disappointed are dissatisfied with the system and the implications of the prevailing technological paradigm. The time is now favourable for political and ideological confrontation to come to the fore (Perez, 2002, p. 55). 


\section{Figure 1: The phases of a "surge of development"}

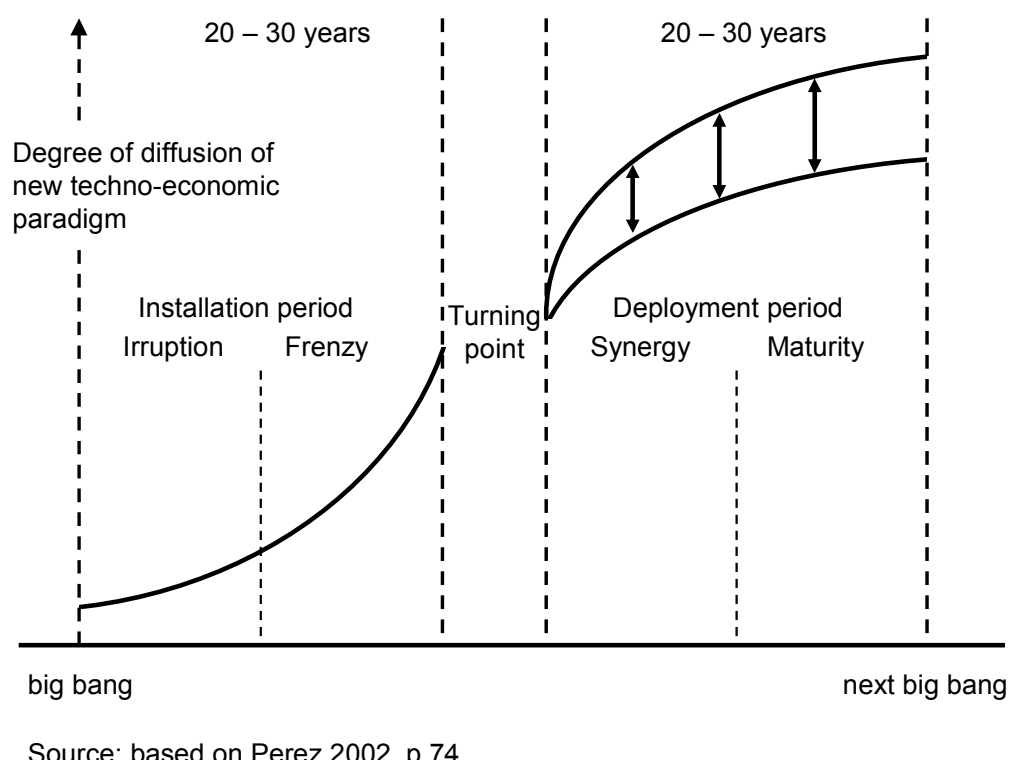

The installation and the deployment phases are separated by a "furning point", which is actually not a point in time but a period of variable length in which a new balance between individual and social interests within capitalism must be found. The burst of the frenzy's bubble will be followed by a deep recession or even depression, and it becomes increasingly apparent that the existing regulatory and social model restrains the exploitation of the full economic potential of the TEP that is taking the lead in economy and society. Here a difference to Schumpeter's model of long waves comes to the fore (Freeman in FCP, p. 141f): what for Schumpeter is the downsizing and depression of the long wave is in Perez's model, the turbulent period of introducing a new paradigm that is forcing its way with the help of finance. This is the time of re-regulation of the economy and of adjusting the institutional framework to the requirements of the now dominant TEP. Richard Nelson emphasises this aspect in his contribution "Technology, Institutions and Economic Development" (Nelson in FCP, 269ff), by pointing out that ithe employment of 'physical' technologies requires the use of complementary 'social' technologies, and the latter, in turn, require a set of supporting institutions." Thus, institutional and regulatory decisions have a strong impact on the degree of diffusion and on the scope of use of the no 
longer new technology, and, even more significantly, on the degree to which a society can benefit from the TEP during the synergy and maturity phases.

The space between the two upward-sloping curves in the right part of the diagram reflects the range of possible outcomes from different regulatory regimes, and the arrows mark the potential impact of policymaking on finding the - more or less - appropriate set of institutions to accommodate the prevailing TEP. This illustrates that the Perez model is not deterministic, but merely indicates that all TEPs - whether steam or railways, steel or mass production - go through similar long-term cycles. This repetitiveness is the very logic of capitalism (Perez, 2002, p. 166).

But there is no guarantee that, after the turning point, a golden age will set in automatically and that the benefits of the new paradigm will be spread equally across all nations. While a turning point and the need to accommodate to the new paradigm opens a chance for economically lagging nations to start a catch-up process, those countries that do not succeed in designing a proper institutional framework may find themselves at least relatively stagnating in a gilded age. The situation is complicated as institutions that work well in one social-political-economic context cannot necessarily be transferred and adapted to the conditions of another (Nelson in FCP, p. 283). So the development path a country adopts depends on decisions in society.

\section{Techno-economic paradigms and the financial markets}

The inevitable cyclical behaviour of the economy - which is a major feature of the Perez model - is not only due to changes in the technoeconomic sphere but also to changes in the financial economy. This aspect is highlighted in Jan Kregel's contribution "Financial experimentation, technological paradigm revolutions and financial crises" (Kregel in FCP, p. 203ff). Financial capital commands technological and economic development in the installation phase of a great surge that leads to the build-up of a bubble. Inflation of assets' paper values relative to real values inhibits development as financial capital becomes increasingly geared towards short-term gains from financial speculation. "The full deployment of the installed paradigm thus requires the elimination of the excessive financial layering through a financial collapse, and increased regulation of the financial system through more rigorous government control in a way that does not prevent the full deployment 
of the new technology led by production capital reaping the full economic and social potential of the now prevailing paradigm." (Kregel in FCP, p. 203). But a financial crisis is not only followed by a new set of financial market regulations as in Perez's model, but also by a shift from excessive risk-taking to excessively risk-averse behaviour in the aftermath of a crisis. In Hyman Minsky's terminology, this means that agents turn back from speculative and Ponzi finance to hedge finance: only the safest projects obtain financing.

Thus in Perez's model, the driving force of a surge of development is a new TEP in the production sector of the economy, while Kregel - based on Minsky - emphasises the importance of innovation in the financial sector. The recent surge, driven by the information- and communication technology (ICT) paradigm has a distinctive feature as the ICT paradigm itself has become a powerful tool of financial innovation; but are financial and techno-economic innovation coincidental or systematic? In a review of the two TEPs that have taken place in the $20^{\text {th }}$ century (mass production and ICT), Kregel shows that the major activity of banks is no longer to provide direct financing for businesses and households but instead to create financial assets that are sold to a subsidiary, which in turn sells them in the capital market to non-bank financial institutions or to the general public (Kregel in FCP, p. 219).

Kregel concludes that the emergence of a new paradigm of creation of liquidity through structured lending vehicles and its interaction with the introduction of new ICT was the important determinant of the development of financial markets during the installation phase of the prevailing TEP. Therefore it seems that Perez's model of techno-economic innovation and Minsky's idea of the crucial role of financial innovation are complementary.

\section{Role of the state and public management in the prevailing ICT-based techno-economic paradigm}

A change of TEP has widespread implications for public policy that reach far beyond regulating the financial system and implications for managing public-sector activities. As creative destruction and innovations release a dynamic that entails strong path dependencies and barriers to entry for competitors, Rainer Kattel claims in his contribution "Small states, innovation and techno-economic paradigms" (Kattel in FCP, p. 190ff) that a public-sector-led process of "creative destruction management" 
is necessary. The public sector should be given a prominent role, particularly in supporting the creation of new knowledge, companies, and jobs, and in alleviating destructive effects. While the ICT revolution may have caused the "death of distance", this revolution has also led to a "rebirth of size" as a key factor for geopolitical units to take into account for innovation and economic policies. This tendency has been reinforced by the international policy environment (the "Washington Consensus") and the increase in financial fragility. As country size is once more a key determinant for company-level innovations, innovation policies should be geared towards the creation of local networks that should be scaled up into wider markets (Kattel in FCP, p. 199).

The role of public policy in innovation is further specified by Claude Rochet and Bengt Åke Lundvall. In Rochet's essay "Carlota Perez's contribution to the research programme in Public Management: Understanding and managing the process of creative destruction in public institutions and organisations" (Rochet in FCP, p. 389), innovation policy works at three levels: At the macroeconomic level, a policy is required that sustains and funds a political strategy to lead the way in innovation, at the meso-economic level, technological clusters should be organised that enable firms to innovate and encourage cooperation, and at the microeconomic level, a business intelligence policy is required that may help individual firms to successfully compete in the "innovation game". Upgrading the competencies of the low-skilled workers and delegating responsibility to them is considered an important component of innovation strategies with an impact on all three levels in Lundvall's essay "Why the new economy is a learning economy" (Lundvall in FCP, p. $221 \mathrm{ff}$ ), because innovation is not only science-based but also thrives in firms that combine science-based learning with experience-based learning.

Such a policy could be more than merely innovation policy, forming the core of a macroeconomic strategy, too. Investment in skills plus public programmes that stimulate firms to engage in organisational change and market-oriented innovation could be the roots of a new kind of Keynesianism. This would stimulate the economy in a situation when traditional economic-policy strategies, such as monetary policy, are ineffective, and at the same time it would facilitate full exploitation of the productivity potential of ICT in the deployment phase of the prevailing TEP. In his essay "Governance in and of techno-economic paradigm shifts: Considerations for and from the nanotechnology surge", Wolfgang 
Drechsler (in FCP, p. 95ff) suggests that sthe regard in which the state and its power are held, the attitude towards the state and its power ... is indeed a matter of the period, not the paradigm. In the installation period, there is 'state distance' ... while the deployment period is denoted by state closeness."

What does this mean for public management? While in the prevailing surge of development, there has been a time lag between the evolution of the state and change in the industrial sector because the production methods of firms engaged in information technology have been affected first, while another and more problematical reason for the time lag has been institutional inertia (Rochet in FCP, p. 375). Perez's model, which is rooted in evolutionary economics and cycle theories, focuses on the need for institutional change and for re-designing the organisation of the economy to cope with the challenges of a new TEP. The efficiency of government activities has not been explicitly targeted in this model, and nor has it been neglected; efficiency would be reached if the society succeeds in creating the appropriate institutional setting for public policy (which seems to be particularly difficult in highly developed countries as institutional inertia there is likely to be fostered by strong vested interests; Rochet in FCP, p. 377).

This is in stark contrast to many of the ideas of New Public Management (NPM), which has been a leading concept of mainstream economics being applied to the public sector. The state's inevitable problems in coping with the challenges of a new TEP have been considered ceteris paribus (i.e. when the organisational structure is not adapted) as a fundamental inability of the state to deal with these problems. This has become a pretext for eliminating the state in the »bureaucratic euthanasia of the state (Rochet in FCP, p. 374). Consequently, the application of NPM has aimed explicitly at raising the efficiency of the public sector (i.e. the administration) by introducing market mechanisms to its operation. NPM thus is an expression of "state distance", which, according to Drechsler, might have been appropriate in the installation phase of the prevailing TEP, but which is no longer appropriate at the beginning of the deployment phase. It fits into this context that, in the current situation, Rochet calls for applying a mix of three disciplines to combine the evolution of institutions and the evolution of organisations (Rochet in FCP, p. 389): public-policy evaluation to analyse the link between outputs and outcomes of government policies, 
organisational efficiency to develop organisational learning so that public organisations can cope with their changing missions, and management control to achieve best-value policy results.

For public management, this implies that effectiveness must once more be given top priority, as opposed to efficiency of government activities. In the prevailing TEP, it also means that the application of ICT is much more than a mere instrument for cutting costs and improving efficiency: The transformational potential of ICT must be utilised by turning it into an endogenous lever of innovation, which makes things possible that otherwise would not have been. One of the main failures of the NPM mainstream, Rochet (in FCP, p. 390) claims, sis its policy of outsourcing IT to the private sector, which has deprived the public sector of the strategic capabilities to manage IT... « In addition, ICT makes it possible to produce an overall design for processes and to align this with strategic objectives (e.g. in a balanced scorecard), thus enabling organisations to become efficient.

\section{What's next - preparing for the next techno-economic paradigm}

While it is undisputed that ICT has been the key technology in the context of the prevailing TEP, it is not yet clear which will be the key technologies of the next surge of development - technologies that, according to Perez's model, should be well known in their fundamental characteristics in the deployment phase of the prevailing (ICT) paradigm. From a careful study of economic stages, "Production-based economic theory and the stages of economic development: From Tacitus to Carlota Perez", Erik S. Reinert concludes that future TEPs are likely to be more research-intensive and more patentable than previous TEPs (Reinert in FCP, p. 369). Perez herself (2010) has recently argued that, motivated by increased interest and concern about the ecological environment, future key technologies will comprise a mix of biotechnology, nanotechnology, bioelectronics, new materials, and new energy sources, and that all these technologies can be related to process industries based on natural resources.

The case for nanotechnology being a candidate for the key technology of the next surge is made by Drechsler. Although other highly dynamic technology fields exists, and although in the past prominent candidates have failed to succeed (e.g. nuclear power in the 1960s and 
1970s), he finds several reasons in favour of nanotechnology. The idea of nanotechnology as the key technology is realistic and possible from today's point of view, and nanotechnology has the potential to radically change and transform the Lebenswelt of mankind, and not just the economy. It presents a logical continuation of TEPs as it promises to solve problems of the mass-production surge related to materials and energy (which have not been solved by the ICT paradigm), and also promises to solve some of the problems of the ICT surge itself (Drechsler in FCP, p. 97). If nanotechnology will become the key technology of the next surge, it is still highly speculative to ponder the question of how to prepare now for an era which will only begin in 20 to 30 years.

A few insights, nevertheless, might be derived from some of the attributes of nanotechnology. In contrast to the ICT paradigm, nanotechnology will bring "a return to the physical, for what is central here is substance, material, things, everything that belongs to the 'real world', including the human body" (Drechsler in FCP, p. 98). This implies a higher degree of necessity of gathering at specific places, and consequently a physical clustering of production and life can be expected. More insights about the role of the state are derived directly from Perez's model: During the period of preparation of a new TEP, the state ought to reduce the risk that the nation and its economy miss out on progress, and to prepare appropriately for the new paradigm. The state's task now would be to make major investments in the nanotechnology sector, which should not be motivated by the urge to become lucrative, or rather, only lucrative in the long run and subject to a high risk level. Thus a long-term perspective is required, as well as state actors (civil servants in particular) with sufficient competence, and a research and policy climate that tolerates mistakes at this very stage of basic research activities (Drechsler in FCP, p. 101f).

\section{Applying the concept of techno-economic paradigms: The case of Latin America}

More concrete aspects of applying the TEP and development-surge concept to future techno-economic development are discussed in the context of Latin America in several essays that reflect Carlota Perez's work on policy advice. José Cassiolato, Carlos Pagola and Helena Maria Lastres (in FCP, p. $51 \mathrm{ff}$ ) discuss the similarities between Perez's model and the Latin American Structuralist Approach (LASA) in their essay "Technical 
change and structural inequalities: Converging approaches to problems of underdevelopment". The basic ideas of the LASA approach are the central role of technical change for explaining development, and specific knowledge and policies towards structural change, and the proposition that "underdeveloped" countries are significantly different from advanced ones and thus cannot follow the same development path (Cassiolato et al. in FCP, p. 52). Perez has enriched the LASA approach by explicitly considering the financial dimension of development.

In a recent paper, Carlota Perez (2010) came up with a summary of a dual development strategy for Latin America, based on STI-type policies (Science-Technology-Innovation) in resource-based processing industries by specialising on high-value-added products. As an implication of the increasing globalisation during the implementation phase of the ICTparadigm, and as an answer to the related hypersegmentation of markets, value chains, and technologies, a top-down strategy should promote the competitiveness of these Latin American industries in the world market. At the same time, a bottom-up strategy should be pursued, through which economic activities at the local level should be promoted. Gabriela Dutrénit and Alexandre Vera-Cruz (in FCP, p. 105ff) agree in their contribution "Innovation policy and incentives structure: Learning from the Mexican case" that this strategy is very suggestive because it builds on Latin American factor endowments as it positions these endowments strategically as potential strengths of the region in the possible new TEP. Drawing on experience from Mexico, they demonstrate that breaking inertias and acquiring a long-term vision, generating consensus between the main agents, and risk-taking in local and national governments are key conditions for success. It has been particularly problematic that Latin American governments have been very sceptical towards STI as a way to solve labour market and poverty problems (Dutrénit \& Vera-Cruz in FCP, p. 122).

Based on Perez's model of development surges, Michael Hobdayin FCP, 145ff) shows in his paper "Asian innovation experiences and Latin American visions: Exploiting shifts in techno-economic paradigms", that Latin American countries should not try to copy the development strategies of Asian countries. The dual development strategy aims at gradually transforming the economy to producing high-value-added-goods in natural-resource-based industries for which demand in the world markets will continue to grow because of strong economic growth in many Asian 
countries. Latin America countries should therefore adopt existing ICT and the related TEP, which is approaching the deployment phase now, to develop capabilities in these resource-based processing industries, and should try to gain a foothold in the industries and technologies that will be the key factors in the next surge of development. Thus, rather than calling on these countries to compete with Asia, Perez's model would call for complementary strategies to exploit international demands and imbalances in technology, trade, and investments of this kind (Hobday in FCP, p. 166).

\section{Conclusion}

As a whole, this volume is most remarkable: The 20 papers in the book highlight many features, possible applications, and give a comprehensive overview of the significance of Carlota Perez's model for understanding long-term techno-economic development and for formulating related strategies. The recent disturbances in the financial markets and in the world economy should have made it clear how relevant both Perez's model and its discussion in the volume are for finding answers to key questions of economic policy. In contrast to other books commemorating a birthday of this kind (which are usually compilations of papers more or less (un-)related with each other), every essay in this volume is focused on the TEP topic, which makes this Festschrift an outstanding collection. 


\section{Walter Scherrer \\ Surges of Development and Techno-Economic Paradigms. \\ A Review Essay of the Festschrift for Carlota Perez.}

\section{Bibliography}

- Cassiolato, J. E., C. Bianchi Pagola \& H. M. Martins Lastres. (2009). Technical Change and Structural Inequalities: Converging Approaches to Problems of Underdevelopment. In FCP, 51-68.

- Drechsler W. (2009). Governance of Techno-Economic Paradigm Shifts: Considerations for and from the Nanotecfhnology Sector. In FCP. 95-104

- Drechsler, W., R. Kattel \& E. Reinert (Eds.). (2009). Techno-Economic Paradigms. Essays in Honour of Carlota Perez. London and New York: Anthem Press; in the article quoted as: FCP [Festschrift for Carlota Perez]

- Dutrenit, G. \& A. O. Vera-Cruz. (2009). Innovation Policy and Incentive Structures: Learning from the Mexican Case. In FCP, 105-124.

- Freeman, Ch. (2009). Schumpeter's Business Cycles and Techno-Economic Paradigms. In FCP, 125-144.

- Hobday, M. (2009). Asian Innovation Experiences and Latin American Visions: Exploiting Shifts in Techno-Economic Paradigms. In FCP, 145-170.

- Kattel, R. (2009). Small States, Innovation and Techno-Economic Paradigms. In FCP, 189-202.

- Kregel, J. (2009). Financial Experimentation, Technological Paradigm Revolutions and Financial Crises. In FCP, 203-220.

- Lundvall, B.-A. (2009). Why the New Economy is a Learning Economy. In FCP, 221-238.

- Nelson, R. R. (2009). Technology, Institutions and Economic Development. In FCP, 269-286.

- Perez, C. (2002). Technological Revolutions and Financial Capital - The Dynamics of Bubbles and Golden Ages. Cheltenham, UK: Edward Elgar.

- Perez, C. (2010). Technological dynamism and social inclusion in Latin America: a resource-based production development strategy. CEPAL Review (100), 121-141.

- Reinert, E. S. (2009). Production-Based Economic Theory and the Stages of Economic Development: From Tacitus to Carlota Perez. In FCP, 333-372.

- Rochet, C. (2009). Carlota Perez' Contribution to the Research Programme in Public Management: Understanding and Managing the Process of Creative Destruction in Public Institutions and Organizations. In FCP, 373394. 